\title{
Survey on the Implementation of Flipped Classroom and Countermeasures
}

\author{
Xiaohui Yang ${ }^{1, a}$, Yuting Shen ${ }^{1, b, *}$ and Yusi $W^{1, c}$ \\ ${ }^{1}$ Hohai University Changzhou Compus, Xinbei District, Changzhou ,Jangsu Province, China \\ a2773354548@qq.com, bguniver@qq.com, c1294054460@qq.com \\ ${ }^{*}$ Corresponding author
}

Keywords: Flipped Classroom, Implementation, Countermeasures.

\begin{abstract}
Flipped classroom is a teaching mode that promotes students' self-learning. It has been promoted and developed in our country. While this teaching mode has received widespread attention, the problem of 'endemic' in its implementation is also very important. Through the methods such as literature, questionnaire and experimental research, we make a survey on the implementation of flipped classroom in colleges and analyze the advantages and disadvantages of its implementation. Based on the analysis above, we also propose some countermeasures, such as adding information-based teaching support, enhancing teachers' ability, optimizing teaching mode, and improving teaching evaluation system.
\end{abstract}

\section{Introduction}

Flipped classroom refers to a process of converting the initiative from teachers to students. It uses a new way that students study by themselves before class and communicate with teachers in the class to replace the traditional teaching model. This kind of teaching model derived from the United States in 2007 and gradually spread to all of the world. At that time, two teachers from the "Woodland Park" high school attempted to reverse the traditional teaching model. They allowed students to study independently through online video, homework, and courseware, while the class time was used to solve problems. Amazingly, the teaching effect was so good. The model began to be promoted in American schools and gradually gained the global recognition[1].

The flipped classroom brings about a nationwide education revolution. The new learning concepts such as self-directed learning, personalized learning, and cooperative inquiry advocated by them are all reasonable and scientific. It cannot be denied that there are some technical defects in the implementation of the flipped classroom. Therefore, the initiative and advantages of its implementation are also greatly affected. Under such circumstances, it is particularly important to study the implementation effects of flipped classrooms and evaluate them to give specific recommendations. The evaluation of the implementation effect is an important part of the teaching process, and it is also an important basis for improving the curriculum.

Regarding to the flipped classroom, domestic and foreign scholars have conducted a lot of researches. Zhang Jinlei (2012) believes that the implementation of flipped classrooms has problems such as unreasonable schedules and lack teaching competence[2]. Therefore, it is particularly important for schools to adjust to local conditions, establish a new teaching philosophy and improve the ability to implement flipped classrooms (Zhu Hongjie, 2013)[3]. With the further promotion and improvement of the flipped classroom, the transformation of the roles of teachers and students and the cultivation of student abilities have become a new focus. (Zhi Zhiting, 2015)[4]. Sun Feng (2015) believes that it is imperative to reverse the localization of the classroom. It should adhere to the process-based and technical assistance[5]. In the domestic and foreign scholars' research on flipped classrooms, most are based on the perspective of teachers. To a certain extent they are separated from the very important target audience, students. We try to study the current implementation of the flipped classroom from the student's point of view, evaluate the implementation effect, put forward 
some practical and feasible countermeasures and constantly improve the theoretical system of the flipped classroom in China.

\section{The implementation of the flipped classroom}

The object of this survey is the students of a university. We try to research the implementation status and effect of the flipped classroom from the perspective of students. Using the advantage of direct audience, we can know about the problem of the flipped classroom and obtain the first-hand information on the experience of flipped classroom, which is of great significance for measuring its teaching effectiveness.

After analyzing the survey data, we find that students generally believe that will they spend more time on learning in the curriculum. What's more, the enthusiasm of the discussion has increased and the cooperative learning and exploration among the students has enhanced in the flipped classroom. This model allows students to think before class, and then they can form a team to discuss and solve problems in class. At the same time, teachers can provide guidance directly in the classroom and answer questions that students are confused about[6]. Overall, students' enthusiasm and initiative of learning have greatly improved.

In terms of student learning results and abilities, flipped classroom has also played a very significant role. Our survey found that nearly $60 \%$ students think their enthusiasm of learning has improved. Half of the students think that their teamwork ability and learning ability have improved. Only a few students think that they have not improved any ability. The survey can intuitively reflect that the flipped classroom will improve the students' abilities, but it also has certain shortcomings, the development of scientific research ability should be the focus of the study.

However, in the investigation we also find that there are some problems in the flipped classroom. A large number of students say that they feel overwhelmed in the flipped classroom. At the same time, many students also feel puzzled and confused. Although some students have a positive perception of the flipped classroom, it is necessary to take students' feelings into account in the process of instructional design[7]. Generally, students are satisfied with the flipped classroom. But flipped classroom as a new teaching mode requires students to invest a lot of energy, so it is inevitable that students will feel uncomfortable and over-stressed. These are problems that need to be resolved during the exploration of the teaching mode.

\section{The dilemma of flipped classroom}

\subsection{Existing teaching facilities and network environment are not perfect}

Flipped classrooms has a strong dependence on hardware facilities. Although network facilities are not necessary conditions for flipped classrooms, they can provide great convenience anyway. In some foreign countries, technical equipment has been fully equipped. However, the development of the flipped classroom in China is not mature, so the various universities in China differ greatly in the allocation of teaching hardware. The facilities of universities in Beijing and Shanghai are relatively completed, while the educational facilities in underdeveloped areas is relatively backward. Therefore, it is more difficult to carry out flipped classes in the middle and western regions. At the same time, many schools have problems such as expensive Internet access, slow Internet speed, imperfect learning platform construction and incomplete functions, all of which have reduced teaching effectiveness.

\subsection{Teacher faces great challenges}

Different from the traditional teaching model, flipped classroom seems to require less teacher participation, but it is actually a huge challenge on the teaching model. On the one hand, teaching ideology has tremendous changes. The role of teachers has changed from the initiator to the guide. This seems to be a simplification of the teacher's work, but in reality it means a higher requirement for the competence of the teacher [8]. Teachers need to abandon traditional teaching thoughts and 
participate in teaching reforms actively. On the other hand, it challenges the comprehensive ability of teachers. Flipped classroom requires teachers to produce videos, design teaching tasks, organize class discussions, answer questions and so on. In many cases, this model not only requires teacher to have a deep understanding of the professional field, but also requires teacher to have the comprehensive ability of cross-professional and interdisciplinary, which is very necessary. In addition, the use of modern information-based teaching equipment is a difficult problem for many teachers.

\subsection{The teaching model is difficult to accept}

Flipped classroom has overturned the traditional teacher-centered teaching model. For students, under the traditional teaching model, they only need to prepare for class before class, attend classes and review. However, in the case of flipped classroom, students need to preview, prepare lessons, speck in class and communicate, make summary after class and so on. There is no doubt that the burden on students becomes heavier. So the Flipped Classroom not only focuses on the process of teaching, but also pays more attention to students' absorption of knowledge, students are no longer just participants in the classroom but are the leaders in the classroom. The new role also gives students new tasks. Students need to participate in the teaching process, due to the lack experience, preparation of teaching content takes a lot of time for students. This will undoubtedly occupy students' after-school hours and aggravate students' academic burden. And in the results of the statistics, many students reflect this new teaching method makes the teaching content more difficult to grasp. Because it is difficult for students' professors to reach professional standards, it is often hard to control the progress of teaching and master the methods of teaching to attract students' attention. Problems such as aggravated burdens make flipped classroom difficult to be accepted by followers of some traditional teaching modes, and even lead to rejection.

\subsection{The assessment criteria are difficult to determine}

In the traditional teaching mode, the evaluation methods for students are mainly examinations, and the assessment standards for teachers are mainly evaluated by the effect of professors. The traditional assessment methods are not apply to flipped classroom, because the student's assessment not only determined by the test scores, but by the student's performance in class. This diversified assessment method can more comprehensively identify students' abilities, and this assessment method can also encourage students to develop in comprehensive way. However, the evaluation method of the examination has been deeply ingrained in China. The evaluation method of flipped classroom is not completely innovative, and the assessment method that combines the test score with the usual achievement is more often used. In the survey, some students believe that the flipped classroom assessment method is not objective and fair, because the proportion and scores of the usual grades are judged by the teacher. In this way, teachers' subjective factors will affect the student's score. Therefore, the implementation of the flipping classroom needs a diversified and fair evaluation method.

\section{Suggestions}

\subsection{Adding information-based teaching support}

Information hardware and software equipment support is the implementation basis of flipping the classroom. In the current teaching information system, courseware, video, and extended data have corresponding entry points, but in practice, many effective module functions are not used. Therefore, in terms of hardware, schools should deploy high-performance servers, widen the campus network bandwidth to ensure smooth video playback, and prepare specialized multimedia classrooms to provide learning conditions for students without hardware devices. In terms of software, the school has established a mature and advanced learning platform to ensure the release of teacher videos and the management of student communication platforms. At the same time, the school should train 
teachers in online learning system operation so that teachers can use the corresponding software equipment in the most efficient way and better guide students in the system to learn after class.

\subsection{Enhancing the teacher's ability}

Teachers should master multimedia and network technologies, improve the ability to flip the video design of courses, pay attention to the core content of the course condensed into the appropriate length of the video. The after-school tasks should be designed to help the students to detect, understand the problems and master the knowledge. It's important to improve the ability of organization communication. At the same time, teachers needs to pay attention to the improving and updating of their personal ability.

\subsection{Optimizing Teaching Mode}

Students can use the online learning platform to prepare for requisites before class. In order to strengthen students' consolidation of knowledge, teachers set up quantifiable evaluation indicators for self-learning before class and use evaluation indicators to reflect the level of self-learning of students. Teachers can use the e-learning platform to set up corresponding goals and problem modules so that students can learn independently before class and they can have a clear understanding of the classroom content and find problems. Teachers should respect the students' cognition, initiate classroom inquiry activities creatively, allow students to take the initiative to participate, explore independently, and guide students to engage in 'dialogue' in exchanges and cooperation, and complete the exchange of ideas and knowledge within the dialogue. In this process, teachers can implement two different teaching strategies to solve students' problems in their study in class. The first one is a pilot-type problem structure in which teachers provide questions to students in advance. Students are encouraged to try to solve problems on their own and lessons are explored against vague local exchanges. Second, students and teachers work together to supplement the designed problem support and discuss these issues in the classroom.

\subsection{Improving the teaching evaluation system}

The flipping classroom focuses on the process of students' internalization of knowledge. Although the students in the survey tend to use the traditional assessment methods for grades and examinations in practice, various assessment methods can be set for flipped classrooms. The evaluation methods can be diversified. Not only can they be used for conclusive assessments, that is, tests, papers, reports, etc., but also can be conducted through peer evaluation and self-assessment. At the same time, the use of classroom online quantitative evaluation functions, such as online time, number of chapters that have been learned, and number of speeches in the discussion area, are used to evaluate student learning activities. Teachers can set different weights for each session, and ultimately evaluate students' learning effects and flipping classroom implementation effects.

\section{Conclusion}

Flipped classroom is an innovative teaching method that is different from traditional teaching. In the process of implementation, many problems will inevitably arise, such as incomplete information equipment, unfamiliar teaching model, and unsound assessment criteria. Based on the results of the survey, this paper proposes very practical suggestions on these issues. In the future flipped classroom as a new teaching mode will be more widely used.

\section{References}

[1] He Chaoyang, Qu Yufang, and Cao Qi, Inspiration of USA Universities' Inverted Classroom Teaching Model, Higher engineering education research,vol.145(02), pp. 148-151+161, 2014.

[2] Zhang Jinlei, Wang Ying, Zhang Baohui, Introducing a New Teaching Model: Flipped Classroom, Remote education magazine, vol.30, pp.46-51, 2012. 
[3] Zhu Hongjie, Zhu Yun, A Discussion on Flipped Classroom and Its Effective Implementation Strategy, Electrochemical education research,vol.34, pp.79-83, 2013.

[4] Zhu Zhiting, Guan Jue, Qiu Huixian, Domestic Application Practice and Reflection in Flipped Classroom, Electrochemical education research,vol.36,pp.66-72, 2015.

[5] Sun Feng, Long Baoxin, The Rational Reflection and Localization Construction of Flipped Classroom, Electrochemical education research, vol.36, pp. 83-88,2015.

[6] Cai Baolai, Zhang Shiya, Yang Yi, MOOCs and Flipped Classroom : Concepts,Basic Characteristics and Design Strategies, Educational Research, vol.36, pp.82-90,2015.

[7] Wang Runlan, Zhang Zhenguo, Ma Yanbin, Song Xiao, The Analysis of the Influencing Factors about Classroom Teaching Implementation in Flipped Classroom of University-Tracking Research Based on 27 Courses of X University, China electrochemical education, vol.371, pp.131-137, 2017.

[8] Wang Oiaohuan, He Chunfeng, Yu Rong, Impact and Challenge of the flipped classroom on the Traditional Teaching Model of Universities, Journal of yangzhou university (higher education research edition), vol.22, pp.102-106, 2011. 